\title{
O PROCESSO DE CONQUISTA DO TERRITÓRIO DOS AKWẼ-XERENTE NO ESTADO DO TOCANTINS ${ }^{1}$
EL PROCESO DE CONQUISTA DEL TERRITORIO DE AKWẼ-XERENTE EN EL ESTADO DE TOCANTINS
THE PROCESS OF CONQUERING THE TERRITORY OF AKWẼ-XERENTE IN TOCANTINS STATE

Layanna Giordana Bernardo Lima²

\begin{abstract}
RESUMO: Este texto é uma parte da pesquisa de doutorado em Geografia Humana, cujo objetivo é estudar as transformações sociais, econômicas e ambientais vivenciadas no território dos Akwẽ-Xerente. Assim, será apresentada a história de contato e conquista do território dos Akwẽ-Xerente, no centro-oeste do estado do Tocantins, marcada por grandes conflitos com fazendeiros, grileiros e posseiros. Para as análises e entendimento desses conflitos, foram utilizados como referenciais teóricos os estudos de Chaim (1983), Gallois (2004), Ribeiro (1996), Apolinário (2006), De Paula (2000), Oliveira-Reis (2001), Martins (2012), dentre outros. Atualmente, os AkwẽXerente têm como grande desafio a permanência da organização política e da língua entre os jovens indígenas e a sobrevivência econômica e social dentro e fora do seu território. Essa problemática foi construída, principalmente, nas interferências das políticas públicas federais e suas alterações nas relações com o Estado e na cultura de massa capitalista invadindo o cotidiano dos Akwẽ-Xerente.
\end{abstract}

Palavras-chave: Akwẽ-Xerente, território, Tocantins, conflitos de terras, cultura.

RESUMEN: Este texto es parte de un estudio de doctorado en geografía humana, que tiene como objetivo estudiar las transformaciones sociales, económicas y ambientales con experiencia en el territorio de Akwẽ-Xerente. Por lo tanto vamos a presentar la historia de contacto y la conquista del territorio de Akwẽ-Xerente, en el centro oeste del estado de Tocantins, marcada por grandes conflictos con los granjeros, los invasores y ocupantes ilegales. Para el análisis y la comprensión de estos conflictos fueron utilizados como marcos teóricos los estudos de Chaim (1983), Gallois (2004), Ribeiro (1996), Apolinário (2006), De Paula (2000), Oliveira-Reis (2001), Martins (2012), entre otros estudiosos. Atualmente la Akwẽ-Xerente tienen que desafiar a la permanencia de la organización política y el lenguaje entre los jóvenes indígenas y la supervivencia económica y social dentro y fuera de su territorio. Este problema pudo haber sidoconstruido principalmente en la interferencia de las políticas públicas federales y los cambios en sus

\footnotetext{
${ }^{1}$ Este artigo integra as análises da pesquisa em andamento em Geografia Humana, orientada pelo Prof. Dr. Ariovaldo Umbelino de Oliveira, do Departamento de Geografia e do Programa de Pós-Graduação em Geografia Humana da Universidade de São Paulo.

2 Doutoranda em Geografia Humana da Universidade de São Paulo e professora da Universidade Federal do Tocantins/Campus de Miracema do Tocantins. E-mail: layanna@uft.edu.br.
} 
relaciones con el Estado y la cultura de masas capitalista invadir la vida cotidiana de Akwẽ-Xerente.

Palabras-clave: Akwẽ-Xerente, território, Tocantins, conflictos de tierras, cultura.

ABSTRACT: This text is part of a doctoral study in human geography, which aims to study the social, economic and environmental transformations experienced in the territory of Akwẽ-Xerente. Thus we will present the history of contact and conquest of the territory of Akwẽ-Xerente, in west-central state of Tocantins marked by major conflicts with farmers, squatters and illegal occupants. For the analysis and understanding of these conflicts were used as theoretical frameworks studies of Chaim (1983), Gallois (2004), Ribeiro (1996), Apolinário (2006), De Paula (2000), Oliveira-Reis (2001), Martins (2012), among other scholars. Nowadays the Akwẽ-Xerente have to challenge the permanence of political organization and language among indigenous youth and the economic and social survival within and outside its territory. This problem may have been built primarily on the interference of the federal public policies and changes in their relations with the state and the culture of capitalist mass invading the everyday life of the Akwẽ-Xerente.

Keywords: Akwẽ-Xerente, territory, Tocantins, land conflict, culture.

\section{Introdução}

Os povos indígenas no Brasil, desde o primeiro contato com os europeus, sofreram com as interferências políticas, sociais e, principalmente, econômicas que transformaram o modo de eles interagirem com o mundo capitalista. De acordo com mapa etno-histórico do etnólogo Nimuendajú (1942), na época da invasão portuguesa havia 1.400 grupos étnicos, 40 troncos linguísticos e cerca de 100 línguas indígenas.

Dados do Censo 2010 do Instituto Brasileiro de Geografia e Estatística (IBGE) indicam um número de 240 povos indígenas em uma população de 896.917 pessoas. Desta população, 324.834 pessoas vivem em área urbana e 572.083 em área rural, o que corresponde a $0,47 \%$ da população geral do País.

Neste trabalho, serão abordadas as características e a vivência dos indígenas denominados Akwẽ-Xerente, localizados no estado do Tocantins, na Região Norte do País. 


\section{História dos Akwẽ-Xerente no norte goiano}

O processo de colonização no Brasil teve como princípio a formação de uma colônia de exploração para o enriquecimento do governo português. As políticas indigenistas e as legislações eram contraditórias e oscilavam entre os interesses dos colonos e jesuítas. Disputa essa que Chaim (1983, p. 67) destaca em seus escritos como uma "luta por mais de dois séculos travada entre colonos e jesuítas, ambos interessados no monopólio do trabalho indígena". Temos também em Melatti (2007, p. 249) a seguinte afirmação:

\footnotetext{
Durante o período colonial, o governo português, no que concerne à legislação sobre os indígenas, oscilou entre interesses dos colonos, que desejavam escravizar os índios, e os esforços dos missionários, que tinham por objetivo convertê-los ao cristianismo e ao mesmo tempo fazê-los adotar os costumes dos civilizados.
}

Somente em $1^{\circ}$ de abril de 1680 pelo Alvará Régio é que Portugal reconhece a posse dos índios às suas terras, considerando-os como seus primeiros ocupantes. Todavia, houve dificuldades no cumprimento desse alvará, pois os colonos não respeitavam a lei e, por sua vez, as autoridades eram omissas.

A Carta Régia de 2 de dezembro de 1808 reconheceu como terras devolutas as conquistadas na batalha com indígenas nas "Guerras Justas". A guerra justa foi uma política indigenista instituída pela Coroa Portuguesa e praticada pelos colonos e religiosos para combater os índios que não se submetiam ao poder de Portugal e que não aceitavam a fé cristã.

Houve muitas leis contraditórias e políticas indigenistas que oscilavam conforme os interesses da sociedade colonial, como os aldeamentos. Estes eram constituídos por índios capturados e administrados pelos jesuítas com objetivo de catequese. Os índios também eram usados para trabalhar nas plantações e demais serviços domésticos. Os aldeamentos eram construídos no entorno dos povoamentos coloniais. 
Os aldeamentos, segundo Oliveira e Freire (2006), eram também empreendimentos econômicos e político-militares. Mas, muitos dos indígenas, mesmo regidos por princípios éticos religiosos, abandonavam com facilidade os ensinamentos que recebiam nos aldeamentos e retornavam às florestas ou invadiam os povoados.

Quanto à questão das terras devolutas, estas ficavam em poder da Corte Portuguesa, que as cedia ou as dava a quem the servisse, ou seja, a quem quisesse. A propósito, Araújo (2006) ressalta que essa ação da Corte Portuguesa de considerar as terras tomadas dos índios como devolutas deu origem a muitos dos problemas de conflitos de terras registrados na história e que incidem até os dias atuais.

Assim, as terras tomadas dos índios, as ditas terras devolutas, eram doadas aos colonos para produzirem e gerar economia para Corte. Para os indígenas, esta visão de propriedade da terra estava distante do seu modo de vida, pois a relação deles com terra era de coletividade e de subsistência, de uso comum. Porém, a colonização trouxe limites territoriais e apropriação da natureza como mercadoria para acumulação de lucro.

Em Marés (2003, p. 50) encontra-se a explicação segundo a qual para os povos indígenas "a terra sempre foi um bem coletivo, generosamente oferecido pelos antepassados que descobriram seus segredos, e legado necessários aos herdeiros que perpetuariam".

Diante dessa realidade de guerras entre colonos e indígenas, bravamente os índios defenderam o seu modo de ser e de viver. Mas os europeus fizeram algumas alianças com tribos rivais que, assim, aumentaram os conflitos entre eles. Para os indígenas, ainda que o inimigo fosse em número relativamente inferior, eles possuíam estratégias de guerras, aliados e tecnologia superior para vencê-los.

Nestes conflitos de vida ou morte, os índios de um lado e os colonizadores do outro punham todas as suas energias, armas e astúcias. Entretanto cada tribo, lutando por si, desajudada pelas demais, exceto em umas poucas ocasiões em que se confederaram, ajudadas pelos europeus que viviam entre elas, pôde ser vencida por inimigo pouco numeroso mas 
superiormente organizado, tecnologicamente mais avançado e, em consequência, mais bem armado (RIBEIRO, 2006, p. 44).

Assim, as políticas de aldeamento e o interesse de desbravamento do Brasil em busca de riquezas fizeram com que fossem organizadas as bandeiras que adentraram os sertões do Nordeste, Centro-Oeste e Norte do Brasil. Aqui, cabe uma explicação acerca das palavras "sertão" ou "sertões" que, na literatura estudada, aparecem em muitos escritos fazendo referências às terras do Brasil Central.

Para além dos aspectos geográficos do sertão, é encontrada em Russell-Wood $^{3}$ (1999 apud APOLINÁRIO, 2006, p. 30) uma definição de sertão como:

[...] terra de ninguém, não cristão, não civilizado e ocupado por seres hostis, despossuídos de valores e princípios da justiça, cristandade e estabilidade, ou melhor, [...] a civilização e a ortodoxia acabavam onde o sertão começava.

Em Oliveira (2004, p. 50) encontra-se a afirmação de como eram vistas as terras para além do litoral em quase todo o processo de colonização e os anos seguintes: "[...] o sertão era representado como lugar onde imperavam o caos, a desordem, o conflito, a violência, a lei do mais forte".

Assim, simbolicamente, no princípio da formação do povo brasileiro foi se formando junto com a miscigenação essa ideia muitas vezes colocada de forma preconceituosa acerca das populações que residiam nos sertões. Não raro, nos dias atuais, as ausências de políticas públicas e sociais, a exploração ilegal dentro de territórios indígenas e conflitos de terras principalmente na Região Norte demonstram que antigas ideias coloniais de exploração e desrespeito perpetuam no tempo.

\footnotetext{
3 RUSSELL-WOOD, Anthony John R. Fronteiras no Brasil colonial. Oceanos, n. 40, p. 8-20, out./dez. 1999.
} 
Entretanto, os sertões foram sendo povoados e mediados pelas relações sociais e econômicas contraditórias dos sujeitos envolvidos nos processos de ocupação territorial e de comércio. Índios, negros e brancos foram responsáveis pela dinâmica política, social, econômica e cultural dos sertões.

O bandeirismo, ironicamente, foi tido como um ato heroico de desbravamento pela sociedade da época, como menciona Chaim (1983). Contudo, os bandeirantes tiveram batalhas violentas com os indígenas, pois o objetivo das bandeiras era capturá-los para escravidão. Os bandeirantes, ao adentrar as florestas, encontraram minas de metais preciosos que aceleraram o processo de ocupação do sertão goiano.

Outra forma de ocupação foi organizada pelos criadores de gado que invadiram os campos dos Timbira. De acordo com Ribeiro (1996), os criadores de gado que vinham com seus rebanhos, pelos rios São Francisco e Parnaíba, do sertão de Pernambuco e da Bahia, passando por Goiás pelas margens do rio Tocantins e descendo ao Maranhão, avançaram até o vale do Itapicuru.

Este processo de contato, apesar de conflituoso, possibilitava aos indígenas no cotidiano e no convívio com os colonos aprendizagens que the serviam como estratégias nos acordos ou mesmo na guerra. No contato interétnico, os indígenas aprendiam principalmente a manusear as ferramentas e a fala da língua do branco para facilitar as relações. Porém, como afirma Ribeiro (1996, p. 73), o "valor do índio como mercadoria não permitia o estabelecimento da paz".

Assim, os indígenas foram conhecendo diferentes formas de ocupação dos seus territórios, as legislações que davam poder aos colonos, as instituições religiosas e as expedições para interior do Brasil. Do mesmo modo, as frentes de expansão extrativista, agrícola e pastoril, lideradas muitas vezes pelos bandeirantes e criadores de gado, foram ocupando os 
sertões. As frentes são mencionadas em Ribeiro ${ }^{4}$ (1957, p. 23 apud MELATTI, 2007, p. 246) como um:

[...] bando de móveis de homens que tendem a desalojar qualquer grupo indígena que por acaso venham a encontrar, tratando de aproveitar suas mulheres como amásias ou produtoras de alimentos, enquanto atraem homens para o trabalho de remeiros, carregadores e outros. Como os bandos de trabalhadores civilizados são pequenos e muitos espalhados, é possível a uma sociedade aguerrida resistir a sua penetração.

Para Martins (2012, p. 9), as frentes de expansão significam, "sobretudo, no que se refere aos diferentes grupos chamados civilizados que se situam 'do lado de cá', um cenário de intolerância, ambição e morte".

Em sua análise acerca dessa relação de expropriação e de exploração da terra e do humano, ele reafirma que a fronteira não é apenas geográfica, mas é:

[...] fronteira de muitas e diferentes coisas: fronteira da civilização (demarcada pela barbárie que nela se oculta), fronteira espacial, fronteira de culturas e visões de mundo, fronteira de etnias, fronteira da história e da historicidade do homem. E, sobretudo, fronteira do humano. Nesse sentido, a fronteira tem um caráter litúrgico e sacrificial, porque nela o outro é degradado para, desse modo, viabilizar a existência de quem domina, subjuga e explora (MARTINS, 2012, p. 9).

Essa definição de fronteira remete a uma relação desumana de dominação do outro pelo poder. O poder que, para Raffestin (2011, p. 52), "visa ao controle e à dominação sobre os homens e sobre as coisas". Foi nesse processo conflituoso de relações que as sociedades indígenas no Brasil foram criando estratégias para permanecerem vivas e lutarem pelos seus territórios.

\footnotetext{
4 RIBEIRO, Darcy; RIBEIRO, Berta G. Arte Plumária dos índios Kaapor. Rio de Janeiro,
} 1957. 
Para Little (2002, p. 4), a análise dos processos diversos das frentes de expansão no Brasil perpassa o entendimento de como "cada frente de expansão produziu um conjunto próprio de choques territoriais e como isto provocou novas ondas de territorialização por parte dos indígenas e escravos africanos". Esse autor ainda ressalta que, para se entender como se deram as formações de territórios desses povos, é preciso analisar dialeticamente o conjunto de contradições nas ações e nas estratégicas de combate que foram sendo criadas pelos povos indígenas e demais grupos tensionados pela ocupação destas terras e pela lógica de acumulação da produção capitalista. Essas relações contraditórias trouxeram novos conhecimentos e visões diferentes de mundos que se confrontavam nas relações entre indígenas, negros, brancos e sertanejos, formando o que Martins (2012) definiu como "fronteira cultural".

No âmbito dos povos indígenas, mesmo apreendendo a língua, cultura e manuseio das ferramentas dos "civilizados", os indígenas não tiveram como se proteger das leis criadas para detê-los, além das moléstias trazidas em seus corpos, que dizimavam tribos inteiras. Muitos eram separados das suas famílias para morar junto aos colonos, quase sempre como escravos. Mas, entre os povos indígenas, como Prado Junior destaca, existiram outras estratégias de contato com a sociedade envolvente:

[...] os índios, que no seu estado nativo já praticavam alguma agricultura, embora muito rudimentar e seminômade, encontraram neste abastecimento dos colonos brancos um meio de obter objetos e mercadorias que tanto prezavam. Muitos deles foram se fixando em torno dos núcleos coloniais e adotando uma vida sedentária. Mestiçando-se depois aos poucos e adotando os hábitos e costumes europeus, embora de mistura com suas tradições próprias, constituirão o que mais tarde se chamou de "caboclos" e formarão o embrião de uma classe média entre grandes proprietários e os escravos (PRADO JUNIOR, 1984, p. 42).

Little (2002, p. 5) detalha que os contatos dos grupos indígenas e negros junto às frentes de expansão resultaram em "resistências, acomodações, apropriações, consentimento, influência mútua e mistura entre todas as partes envolvidas". Soma-se a isso, segundo o autor, a constituição 
de territórios que são criados e recriados na perspectiva das relações sociais e históricas que esses grupos vivenciam, e na constituição evidente da formação da população brasileira que tem suas gêneses nos conflitos de terras.

Esse contexto de conflitos e dominação dos povos indígenas é encontrado nas literaturas histórica, geográfica e indigenista. São registros históricos e estudos acerca da situação dos índios na Região Centro-Oeste do Brasil, principalmente nos aldeamentos do Goiás entre 1749 a 1811 . Fato esse que ajuda a registrar o contato com a sociedade colonial dos povos indígenas existentes atualmente no estado do Tocantins. Ademais, Chaim apresentou em seus estudos como eram organizados os aldeamentos goianos:

\footnotetext{
Os colonos viam no índio um trabalhador aproveitável, a metrópole portuguesa, sobretudo, um povoador para as extensas áreas a serem ocupadas, com elemento participante do processo de colonização. Em Goiás o antagonismo dessas posições resultou em conflitos. O elemento nativo, provocando choques intermitentes com o colonizador, veio a obrigar o governo central a tomar providências. Como solução para o problema, grandes somas foram gastas para aldear o gentio e pacificá-lo (CHAIM, 1983, p. 43).
}

As etnias existentes nessa região, principalmente na Ilha do Bananal, segundo Chaim (1983), eram os Javaé, Karajá, Xavante e outros. Alguns foram dizimados como, por exemplo, o grupo indígena Akroá.

Os Akroá foram dizimados nas fronteiras do sertão das capitanias de Goiás, entretanto, foram resistentes ao projeto colonizador, pois "criativamente souberam resistir aos diferentes eventos das relações interétnicas com a sociedade circundante colonial, seja conflituosa e/ou negociável" (APOLINÁRIO, 2006, p. 242).

De Paula (2000) indica na sua pesquisa acerca dos Akwẽ-Xerente que para compreender o universo dos mesmos precisou construir um arcabouço de informações etnográficas, construído pelas histórias orais indígenas, por 
relatos dos documentos deixados por funcionários do governo da Província de Goiás e por viajantes que percorreram o Centro-Oeste brasileiro durante os séculos XVIII e XIX.

O registro histórico de ocupação dos Xavante na região do estado do Tocantins é relatado por Oliveira-Reis (2001), que afirma que as primeiras menções aos Xavante sempre foram pontuais e que surgiram justamente por volta da metade do século XVIII, quando se iniciam as políticas pombalinas de aldeamentos.

Segundo Oliveira-Reis (2001), citando o estudo de Nimuendajú (1942), entre 1732 e 1738, os arraiais de Crixás, Traíras, São José do Tocantins, Água Quente e povoados que foram destinados ao assentamento de garimpeiros já faziam fronteira com o território dos Akwẽ-Xerente e AkwẽXavante às margens do Tocantins. Os Xavante atualmente residem no estado do Mato Grosso. Os Xavante e Xerente autodenominados Akwẽ, que significa "Gente/Povo", junto com os Xacriabás, são do tronco linguístico chamado Jê Central.

Apolinário (2006), nos seus estudos em busca pelos registros dos povos indígenas que ocuparam as terras do norte goiano, apresenta que:

[...] antes de ser ocupado por aventureiros ávidos por descobertos auríferos, o norte goiano já fora habitado por grupos étnicos, em sua maioria pertencentes ao tronco linguístico Macro-Jê, dentre os quais destacaram-se os Akroá, Xakriabá, Xavante, Xerente, Javaé, Xambioá e Karajás. Somente os Avá-Canoeiros, citados na documentação, pertencem ao tronco linguístico Tupi (APOLINÁRIO, 2006, p. 31).

Para Nimuendajú (1942), os dois grupos tinham a mesma língua e os mesmos costumes. As diferenças estavam relacionadas às formas de organização política e espacial. Assim, o etnólogo indica nos seus escritos que a separação entre os dois grupos pode ter acontecido por volta de 1850, levando os Xavante a seguirem para Oeste, atravessando o rio Araguaia, e os Akwẽ-Xerente permanecendo em ambas as margens do rio Tocantins, sendo que os registros de 1859 já distinguem os Xerente dos Xavante. 
Em relação à separação dos Xavante e Xerente, existem muitos registros, mas não são conclusivos acerca de como se deu esse processo. Ravagnani $^{5}$ (1991, p. 67 apud OLIVEIRA-REIS, 2001, p. 43) indica uma separação geográfica dos dois grupos e que o processo de separação desses dois grupos se deu como uma estratégia diante do contato com as frentes de expansão agropastoris que vinham em sentido Nordeste-Sudoeste. Dessa forma, os Xavante foram migrando para oeste, em direção aos rios Araguaia e, posteriormente, das Mortes, e os Xerente teriam permanecido na bacia do médio Tocantins.

Nos estudos de Ribeiro, os Akwẽ também são mencionados como umas das tribos do Brasil Central. Segundo o autor:

[...] os Akwẽ igualmente como os Timbiras falam a língua da família Jê. Têm uma organização social complexa, baseada num sistema de metades e clãs. [...] ocupavam originalmente a bacia do Tocantins, desde Goiás até o Maranhão, estendendo-se do rio São Francisco ao Araguaia (RIBEIRO, 1996, p. 80).

É preciso ressaltar que quando Ribeiro menciona os Akwẽ, está se referindo não apenas aos Xerente, mas fazendo também referência aos Xavante, pois esses dois grupos tiveram que enfrentar os criadores de gados, garimpeiros que estavam à procura de ouro e de diamantes no Norte da capitania de Goiás, que teve sua criação originária na descoberta de minas e nas explorações dos metais preciosos. A exploração das riquezas desta região, principalmente a da exploração de ouro e a de apropriação de terras para agricultura ou pecuária, gerou muitos conflitos entre indígenas, posseiros, grileiros e fazendeiros.

As missões religiosas tiveram um importante papel no projeto civilizatório dos indígenas por meio da catequese, cujo objetivo era torná-los cristão e trabalhadores. Assim, a Igreja e Estado estiveram presentes nesse

\footnotetext{
${ }^{5}$ RAVAGNANI, Oswaldo M. A experiência Xavante com o mundo dos brancos. Araraquara: Unesp, 1991.
} 
processo de ocupação e formação da capitania de Goiás como nas demais capitanias brasileiras.

Segundo Ribeiro (1996), os Akwẽ tiveram contato com os civilizados por volta de 1785, sendo suas relações pacíficas com o governo da capitania de Goiás. Estiveram no aldeamento de D. Pedro II ou Carretão. Eram numerosos, em torno de 5 mil, e tinham contato com a vida civilizada, ou seja, com os cristãos. Entretanto, Ribeiro menciona que:

[...] ali os Akwẽ tiveram a oportunidade de conviver intimamente com guarnições militares e de experimentar uma vida civilizada. [...] logo depois começaram a escapar rumo ao norte, para o antigo território tribal. [...] um grupo que denotava maior aversão ao convívio com civilizados e que passou a ser conhecido como Xavante começou a se deslocar para a margem esquerda do rio Tocantins (1824), depois para Araguaia (1859), acabando por se estabelecer nos campos dos rios das Mortes.[...] os Akwẽ, que voltaram a se fixar no seu antigo território, à margem direita do Tocantins, passaram a ser conhecidos como Xerente. Estes grupos revelaram maior disposição para conviver com os civilizados (RIBEIRO, 1996, p. 80).

Esta questão envolvendo os Akwẽ-Xerente e Akwẽ-Xavante está presente na memória dos mais velhos, nas visitas feitas nas aldeias em 2012, no início da pesquisa de doutorado que originou este artigo e no convívio acadêmico com os estudantes Akwẽ-Xerente da Universidade Federal de Tocantins (UFT)/Campus de Miracema do Tocantins, que confirmam as considerações feitas por Nimuendajú (1942) e demais autores.

Em uma das visitas na aldeia Porteira, dentro do território dos AkwẽXerente localizado no município de Tocantínia (TO), conseguiu-se conversar com o ancião Severo, que contou como era a relação entre esses dois grupos indígenas:

[...] As etnias viviam juntos, Xavante, Gavião, Krahô, Kaiapo, Xerente, e Morcego, e um dia todos resolveram se espalhar cada grupos, uns foram para mata fechada e assim aconteceu. Os Xavante e Xerente viveram uns tempos junto e alguns tempos os Xavante deixaram os Xerente aqui no Morro 
Perdido. Porque aconteciam os conflitos com os Xavante e os Xerente, e nós ficamos morando no Morro Perdido e depois os invasores das terras que tomaram o local, e viemos afastando até que chegamos aqui nesse lugar. Uma vez fui com antropólogo e não reconheci o lugar, estava limpo, os não índios desmataram, acabou com as árvores, essa é a história dos Xerente com os Xavante, a terra era nossa, hoje estamos morando na reserva [...] (informação verbal ${ }^{6}$ ).

De acordo com o ancião Severo, houve conflitos entre os dois grupos e que Akwẽ-Xerente ficaram perto do Morro Perdido (atualmente este "Morro Perdido" está localizado dentro de uma fazenda no município de Guaraí - TO, localizado às margens da Rodovia BR-153). Esses dois grupos foram se afastando dessa região por causa das "invasões" realizadas pelos colonizadores, aventureiros e posseiros que vinham conquistar as terras e as riquezas do sertão goiano.

Similar ao depoimento do ancião Severo, de 2012, Ribeiro (1996), ao tratar das ocupações das terras do Maranhão e do norte do Goiás, descreve que no final do século XIX quase todas as terras do Maranhão e norte do Goiás já estavam sob o domínio dos criadores de gado.

[...] os grupos timbiras que não quiseram submeter-se tiveram de abandonar os campos fugindo para as matas, como os Krem-yé, que foram ter ao Gurupi, e os Gaviões, que se refugiaram no Tocantins, onde se conservam hostis até hoje (RIBEIRO, 1996, p. 78).

As mudanças constantes de lugar, devido à presença dos criadores de gado e demais invasores, fizeram com que os Akwẽ-Xerente permanecessem por um tempo na região, onde hoje se localiza a cidade de Miracema do Tocantins, localizada à margem do rio Tocantins. Porém, logo pelas mesmas razões anteriores, atravessaram o rio para região da cidade de Tocantínia, local onde tiveram suas terras demarcadas e residem até os dias atuais.

\footnotetext{
${ }^{6}$ Relato do ancião da aldeia Porteira Severo Sôware, no município de Tocantínia (TO), 2012.
} 


\section{Os Akwẽ-Xerente e sua organização política social}

A história de contato dos Akwẽ-Xerente com a sociedade nacional corresponde a aproximadamente 250 anos ou mais. Os povos indígenas em geral e no seu cotidiano utilizam da mitologia para interpretarem o mundo ao seu redor. Analogamente a cosmologia dos Akwẽ-Xerente está diretamente relacionada à natureza. O cosmo dessa sociedade divide-se em três níveis:

a) a Terra (tka);

b) o Céu (hêwa);

c) o Mundo Subterrâneo (tkakamô).

Em Guimarães (2002), é apresentado um breve histórico da etnografia dos Akwẽ-Xerente, tendo como destaque três estudos e momentos históricos:

1. Nimuendajú em 1930 e 1937, trabalho esse que foi traduzindo para o inglês por Lowie e impresso em 1942.

2. Estudo do antropólogo Maybury-Lewis, que esteve com os AkwẽXerente em 1955 e 1963.

3. Estudo do antropólogo brasileiro Farias em 1990, além do trabalho de Lopes e Farias, de 1993, acerca da pintura corporal e da organização social Akwẽ-Xerente.

Nos registros de Nimuendajú (1942) são destacadas com detalhes as questões que envolvem a organização da sociedade Akwẽ-Xerente. Em um dos seus relatos, Nimuendajú ainda menciona que os encontrou vivendo um colapso populacional devido às muitas doenças trazidos pelos não índios.

Oliveira-Reis (2001) descreve em sua pesquisa que a população dos Akwẽ-Xerente encontrada por Nimuendajú, entre as décadas de 1930 e 1940, era de aproximadamente 300 índios. Entretanto, nas décadas de 1950 e 1960 Maybury-Lewis viveu entre os Xerente e encontrou uma população de 330 
índios. Para Oliveira-Reis (2001) esse crescimento irrisório teve sua causa nas epidemias que acometeram os Akwẽ-Xerente.

Guimarães (2002) menciona que para Maybury-Lewis o pensamento dos Akwẽ-Xerente organiza-se na dialética do princípio dual: nós/eles. Essa relação dialética nessa perspectiva dual, nós/eles, tem possibilitado aos Akwẽ-Xerente manterem, mesmo com muitas interferências da sociedade dos não índios, a sua identidade cultural, principalmente a comunicação entre eles por meio da língua Akwẽ e a estrutura social. Nesse sentido, MayburyLewis $^{7}$ (1979 apud GUIMARÃES, 2002) considera que, apesar da intensidade do contato com a população regional, é surpreendente a capacidade de se manterem como uma entidade cultural e linguística diferenciada.

No cotidiano dos indígenas, principalmente entres os acadêmicos indígenas que fazem parte da UFT no campus de Miracema da Universidade Federal do Tocantins, pode-se evidenciar que a organização por clãs e o uso da língua Akwẽ ainda persistem nas relações entre eles. Entretanto, é possível observar nas visitas às aldeias que algumas tradições estão se perdendo. Essa situação é uma das principais preocupações dos mais velhos.

\section{Conflitos de terras}

Os conflitos entre indígenas com europeus, bandeirantes e fazendeiros tiveram início desde os primeiros contatos, como já mencionado. As frentes de expansão agropastoris, de extrativismo e agrícola dos séculos passados deixaram marcas de conflitos. Seja por motivos políticos ou religiosos, todos traziam em sua busca a dominação e a apropriação de terras.

O século XX, segundo De Paula (2000), foi marcado por grandes conflitos entre os Akwẽ-Xerente, fazendeiros e posseiros que pressionavam e invadiam as terras indígenas. Essa expansão territorial sobre as terras indígenas, de acordo com Martins (2012), tem resultado, como antes, no

\footnotetext{
7 MAYBURY-LEWIS, David. Dialectical Societies: The Gê and Bororo of Central Brazil. Cambridge: Harvard University Press, 1979.
} 
massacre das populações nativas e sua drástica redução demográfica e até desaparecimento. Entretanto, atualmente essa expansão territorial pode se renomeada pelas palavras "desenvolvimento econômico" pautado na produção agrícola e de energia.

O progresso por meio das expansões agrícola, de hidrelétricas e construções de estradas e ferrovias na Região Norte nem sempre ou quase nunca teve a preocupação com as populações indígenas ou camponesas.

Os Akwẽ-Xerente, mesmo depois da demarcação do seu território, sofreram com pressões econômicas e impactos ambientais oriundos da criação do estado do Tocantins em 1988, e nos anos seguintes, com a construção da usina hidrelétrica Luís Eduardo Magalhães e outras. E continuam sofrendo com tensões dos projetos de agricultura moderna no entorno de suas terras.

Ainda que a Constituição Federal (1988), em seu artigo 231, reconheça e garanta aos indígenas os direitos originários das terras que ocupam tradicionalmente, competindo à União demarcá-las, proteger e fazer respeitar todos os seus bens, as discussões a que se assistem atualmente acerca dos direitos dos indígenas no Brasil têm demonstrado retrocesso, desrespeito e descaso aos direitos indígenas.

Podemos citar recentemente alguns exemplos e ameaças às terras indígenas:

a) A construção da hidrelétrica no rio Xingu no estado do Pará dentro do território indígena.

b) $\mathrm{O}$ conflito entre indígenas e policiais militares e federais no processo de reintegração de posse de fazenda na Terra Indígena Buriti no estado do Mato Grosso do Sul, que resultou em muitos feridos e na morte de um indígena no final do mês de maio de 2013.

c) As discussões da PEC-215 e da portaria 303 da Advocacia-Geral da União (AGU), que prevê retirar da Fundação Nacional do Índio (Funai) e repassar para o Congresso Nacional o poder de demarcar e fiscalizar as terras indígenas. A primeira já aprovada e a segunda ainda em discussão têm por objetivo aprovar a construção de hidrelétricas, 
rodovias e outros empreendimentos nas terras indígenas sem consulta prévia e de proibir a ampliação de terras em favor dos índios.

Voltando às lutas pelo reconhecimento do território indígena dos AkwẽXerente, os estudos indicam que aproximadamente 200 anos depois do contato com a sociedade é que os Akwẽ-Xerente iniciam um processo de legalização de seu território. De Paula (2000) menciona que a conquista de suas terras somente foi intensificada com apoio da Funai no início na década de 1970, sendo que esse movimento reivindicativo apenas teve resultado final 20 anos depois.

As legislações que garantiram aos indígenas a legalização de suas terras foram as constituições de 1934, 1937, 1946 e 1967. Segundo Oliveira e Freire (2006), a Constituição de 1988 também rompeu com a herança tutelar originada no Código Civil de 1916, mudando o status dos índios, permitindo que individualmente ou através de suas organizações ingressassem em juízo para defender seus interesses. Ainda acrescentam que:

\footnotetext{
Com a Constituição Federal de 1988 rompeu-se a perspectiva integracionista estabelecida desde o SPI [Serviço de Proteção aos Índios]; as terras indígenas seriam definidas desde então como aquelas que possibilitam a reprodução dos índios, isto é, aquelas "necessárias a sua preservação física e cultural, segundo seus usos, costumes e tradições" (OLIVEIRA; FREIRE, 2006, p. 134).
}

Gallois (2004), em artigo da publicação "Terras Indígenas e Unidades de Conservação da Natureza", sobre a questão dos territórios indígenas, coloca que terra indígena não é o mesmo que território indígena. Estudos antropológicos afirmam que a diferença entre terra e território reside nas diferentes perspectivas e sujeitos envolvidos no processo de demarcação da terra. Para Gallois 
[...] a noção de terra indígena diz respeito ao processo político-jurídico conduzido sobre a égide do Estado, enquanto a de território remete à construção e à vivência, culturalmente variável, da relação entre uma sociedade específica e sua base territorial (GALLOIS, 2004, p. 39).

Em continuidade à discussão acerca de território indígena, Haesbaert (2004) dá uma importante contribuição para a compreensão desta temática. De acordo como autor, "território para os indígenas é ao mesmo tempo um espaço de reprodução física, de subsistência material, e um espaço carregado de referências simbólicas" (HAESBAERT, 2004, p. 67).

Para Oliveira (2010), são as relações sociais de produção e o processo contínuo/contraditório do desenvolvimento das forças produtivas que dão a configuração histórica específica ao território; ou seja, o território é o espaço onde permanentemente é travada a luta da sociedade pela apropriação da natureza. Para ele, território deve:

[...] ser apreendido como síntese contraditória, como totalidade concreta do processo/modo de produção/distribuição/circulação/consumo e suas articulações e mediações supraestruturais (política, ideológica, simbólicas etc. ) [...] o território é assim produto de luta de classes travada pela sociedade no processo de produção de sua existência (OLIVEIRA, 2010, p. 74).

Dessa forma, a luta pelo território e modo de vida dos Akwẽ-Xerente foi construída a partir da relação de sobrevivência, humana e cultural. Este povo indígena, tendo em vista as muitas transformações que vivenciaram, foram se reorganizando dentro e fora do seu território.

Os Akwẽ-Xerente, localizados a 70 quilômetros da capital do estado do Tocantins, Palmas, vivem ao leste do rio Tocantins e estão em duas Terras Indígenas: TI Xerente, denominada "Área Grande", com superfície total de 167.542,1058 hectares, que foi identificada oficialmente pela Funai como área ocupada pelos Akwẽ-Xerente em 1972; e a TI Funil, com superfície de $15.703,7974$ hectares, na cidade de Tocantínia, na margem direita do rio Tocantins. 
De Paula (2000) indicou que o território indígena dos Akwẽ-Xerente foi palco de muitos conflitos e olhares nacionais e internacionais para as terras ocupadas por esses indígenas, afinal, suas terras ocupam uma localização estratégica. No entorno dessas terras estão vários projetos de desenvolvimento incentivados pelo governo federal em parceria com a iniciativa privada.

Essa realidade do desenvolvimento econômico causou discordância na população das cidades que fazem divisa com o território indígena e que estão localizadas à margem do rio. Um dos exemplos que se pode citar é o da cidade de Rio Sono, que se encontra no meio de dois rios: rio Sono e rio Perdida. Em visita à cidade, alguns moradores "acusaram os índios" pela dificuldade da cidade em se desenvolver. Eles acham que os índios não permitiram a construção de uma ponte e de uma estrada que poderiam ajudar no desenvolvimento da agricultura local (plantio de soja). A estrada, se construída, iria passar dentro do território indígena. Na verdade, o que aconteceu é que o governo do estado, na época comandado por José Wilson Siqueira Campos, não queria indenizar os indígenas pela construção da ponte e nem pela estrada. A ponte não foi terminada e a estrada nunca foi finalizada.

O comércio da cidade de Tocantínia é principalmente movimentado pelos indígenas, quase maioria da população. O município de Tocantínia é composto de $70 \%$ de Terras Indígenas e, de acordo com os dados do IBGE (2010), sua população aproximada é de 6 mil habitantes. Destes, os AkwẽXerente somam um total de 3.017. Esses dados confirmam que a população Akwẽ-Xerente tem aumentado de forma significante nos últimos dez anos.

As sociedades indígenas passaram por diversas transformações no seu modo de vida desde a colonização até os dias atuais. Todavia, para entender o processo contraditório destas transformações sociais e territoriais é preciso analisar os aspectos propriamente materiais e econômicos desse processo, e não reduzi-lo ao pressuposto de que as sociedades indígenas apenas se preservam no confronto e que não se deixam de algum modo invadir e 
modificar pela mediação direta ou indireta do estranho (MARTINS, 2012). Ao tratar dessas transformações, Little garante que:

As transformações territoriais que a área que hoje é o Brasil sofreu nos últimos séculos estão imbricadas com os incessantes processos de expansão de fronteiras. A história das fronteiras em expansão no Brasil é, necessariamente, uma história territorial, já que a expansão de um grupo social, com sua própria conduta territorial, entra em choque com as territorialidades dos grupos que residem aí (LITTLE, 2002, p. $4)$.

No território indígena dos Akwẽ-Xerente, hoje há aproximadamente 62 aldeias. Os indígenas têm fonte de renda monetária oriunda de aposentarias e pensões, Bolsa Família, serviços públicos estaduais, federais e municipais (professores indígenas, agentes de saúde e saneamento). Em síntese, ao longo da história, os territórios dos Akwẽ-Xerente foram construídos pelo movimento de suas relações com a sociedade nacional e com a natureza. Assim, os séculos XX e XXI trouxeram mudanças no modo de vida dos AkwẽXerente. A esse respeito, Martins destaca que:

As populações indígenas têm mais do que resistido à invasão e à espoliação branca e capitalista de seus territórios. Assim como a violência do branco se manifesta na tentativa de desfigurá-las culturalmente, elas também têm indicado, em suas lutas, o que lhes é insuportável e indecifrável no que para muitas delas é uma nova situação, que é a situação de fronteira, criada pela expansão territorial do grande capital e da sociedade civilizada. [...] aparentemente, em termos muito gerais, o que os povos indígenas estão definindo lentamente, por implicação, em seus confrontos com os brancos é uma situação de convivência marcada pela pluralidade cultural e social e pelo estabelecimento de um espaço inteiramente novo na relação com o outro, que seja um espaço de afirmação e reconhecimento da diferença que dá sentido à existência dos diferentes povos (MARTINS, 2012, p. 26).

Apropriação e exploração da natureza pelo homem devem ser analisadas junto com o processo de globalização e do desenvolvimento da lógica capitalista na sociedade atual. Na verdade, os Akwẽ-Xerente têm resistido, buscado a preservação de sua organização político-cultural. 
Todavia, de acordo com a frequência dos relatos de indígenas, existem algumas preocupações do povo Akwẽ-Xerente. São discutidos por eles as preocupações dos anciões na permanência da tradição por meio dos contos e cânticos obtidos pela "Oralidade dos Anciões". As preocupações dos anciões são pertinentes, afinal, as mudanças em alguns aspectos no modo de vida dos Akwẽ-Xerente é real e presente.

Em síntese, os Akwẽ-Xerente vivem a dicotomia de morarem nas aldeias e terem de atuar politicamente acerca das suas demandas diante das políticas municipais, estaduais e federais.

Diante desse panorama é que Arruda coloca que:

[...] os povos submetidos às pressões da expansão capitalista sofrem mudanças radicais, induzidas por forças externas, mas sempre orquestradas de modo nativo. As dinâmicas internas de produção e reprodução da vida social sofrem adequações gradativas, em grande parte não planejadas, mas sempre criativas às imposições decorrentes dos laços com o mercado e à ininterrupta luta política para a preservação do território tribal e de seus recursos (ARRUDA, 2001, p. 50).

A presença na universidade tem sido uma esperança para os anciões que veem como uma forma do acadêmico indígena falar e escrever a história do seu povo, bem como se apropriar de conhecimentos necessários para mediar suas ações em face das lutas cotidianas: políticas, econômicas e culturais. O que vai ao encontro de Arruda (2001, p. 59) quando menciona que este é um "processo extremamente contraditório e ambíguo e diferenciado em cada grupo e região".

\section{Considerações finais}

As leituras iniciadas para a organização deste texto despertaram para a necessidade do exercício da busca pela compreensão dos fatos históricos de muitas lutas conflituosas que a população da Região Norte tem passado 
em relação às expansões territoriais, às frentes agropastoris e aos empreendimentos grandiosos.

Para compreender como se dão essas relações e como sujeitos são historicamente alijados de direitos e garantias no contexto de desenvolvimento atual do capital, é necessário articulação das formas sociais de pensar o mundo. E ter como proposição entendê-las historicamente, bem como sua geograficidade.

Os sujeitos envolvidos nesse processo dialético de produção e reprodução de sua existência vão construindo suas estratégias de sobrevivência organizando o território onde essas relações vão sendo produzidas e reproduzidas.

Para análises posteriores, deverá ser trabalhada a problemática referenciada pelos Akwẽ-Xerente nas visitas feitas nas aldeias. Os aspectos a serem considerados estão relacionados à permanência da organização política, da língua entre os jovens indígenas e à sobrevivência econômica e social dentro e fora do seu território. Segundo alguns indígenas, esses problemas tiveram origem:

a) Nas muitas interferências das políticas públicas federais e nas alterações de suas relações com o Estado.

b) Nos diferentes programas voltados para a agricultura que foram orientados pela Funai e outros órgãos do governo.

c) No contato com líderes não índios, na proximidade com a cidade e na intensificação das relações econômicas de mercado nas práticas sociais dos Akwẽ-Xerente.

d) Na cultura de massa capitalista em escala mundial, nacional e local invadindo o cotidiano da juventude dos Akwẽ-Xerente.

Os modelos de desenvolvimento econômico adotados pelo Estado capitalista, que têm como viés a lógica da expropriação de acumulação de lucro, têm caracterizado e mudado as relações sociais, políticas, econômicas e ambientais nos territórios indígenas, provocando, segundo Martins (2012, p. 26), "a recriação de mecanismo de acumulação primitiva, confiscando 

Tocantins, pp. 61-85.

terras e territórios, justamente atingindo violentamente as populações indígenas e camponesas".

Estas populações têm sido muitas vezes resistentes, lutando para que o direito adquirido pela Constituição Federal de 1988 se cumpra. Em contrapartida a estas relações políticas de poder, vão surgindo como no passado novas estratégias de lutas e de organizações sociais com objetivo de sobrevivência vital e cultural diante do processo de desenvolvimento de uma economia baseada na exploração do trabalho humano e no lucro, provocando em muitos casos a escravidão pelo trabalho e por dívida aos agentes financeiros, patrões, donos de terras e demais dívidas produzidas pela sociedade capitalista.

Diante dessa racionalidade, buscou-se para o estudo de doutorado que originou este artigo a compreensão de como se dão estas relações e como sujeitos historicamente alijados de direitos e garantias vão se reorganizar nesse processo de monetarização de sua vida. Esse entendimento apenas será possível nas leituras sociais do contexto do desenvolvimento atual do capital.

Em síntese, podemos afirmar que os Akwẽ-Xerente estão vivendo e se reorganizado dentro e fora do seu território, tendo como desafio a perpetuação da sua cultura e as relações interculturais com a sociedade nacional, com o governo do estado e município, principalmente com as relações políticas e econômicas com a cidade de Tocantínia. Esta metaforicamente sendo descrita como uma grande aldeia dos Akwẽ-Xerente.

\section{Referências bibliográficas}

APOLINÁRIO, Juciene Ricarte. Os Akroá e outros povos indígenas nas fronteiras do sertão: políticas indígena e indigenista no norte da capitania de Goiás, atual Estado do Tocantins, século XVIII. Goiânia: Kelps, 2006.

ARAÚJO, Ana Valéria et al. Povos Indígenas e a Lei dos "Brancos": o direito à diferença. Brasília: Ministério da Educação, Secretaria de 
Educação Continuada, Alfabetização e Diversidade; LACED/Museu Nacional, 2006.

ARRUDA, Rinaldo Sérgio Vieira. Imagens do índio: Signos da Intolerância. In: GRUPIONI, Luís Donisete Benzi; VIDAL, Lux; FISCHMANN, Roseli. Povos Indígenas e tolerância: construindo práticas de respeito e solidariedade. São Paulo: Editora da Universidade de São Paulo, 2001. (Seminários 6; Ciência, Cientistas e Tolerância II).

BRASIL. Constituição (1988). Constituição da República Federativa do Brasil. Brasília, DF: Senado, 1998.

CHAIM, Mariovone Matos. Aldeamentos Indígenas (Goiás 1749-1811). 2. ed. rev. São Paulo: Nobel, Brasília; INL, Fundação Nacional PróMemória, 1983.

DE PAULA, Luís Roberto. Dinâmica Faccional Xerente: Esfera Local e Processos Sociopolítico Nacionais e Internacionais. 2000. _f . Dissertação (Mestrado em Antropologia Social) - Departamento de Antropologia da Faculdade de Filosofia, Letras e Ciências Humanas da Universidade de São Paulo, São Paulo, 2000.GALLOIS, Domini Tilkin. Terras ocupadas? Território? Territorialidades? In: RICARDO, Fany (Org.). Terras Indígenas e Unidades de Conservação da Natureza. São Paulo: Instituto Socioambiental, 2004, p. 37-41.

GUIMARÃES, Susana Martelletti. A aquisição da escrita e diversidade cultural: a prática de professores Xerente. Brasília: FUNAI/DEDOC, 2002.

HAESBAERT, Rogério. O mito da desterritorialização: do "fim dos territórios" à multi-territorialidade. Rio de Janeiro: Bertrand Brasil, 2004.

inSTITUTO BRASILEIRO DE GEOGRAFIA e ESTATÍSTICA. Censo de 2010. Cidades@: Tocantínia. Disponível em: <http://www. cidades.ibge.gov.br/xtras/perfil.php?lang $=\&$ codmun $=172$ 110\&search=tocantins $\mid$ tocantinia $>$. Acesso em: 28 set. 2015.

LITTLE, Paul E. Territórios sociais e povos tradicionais no Brasil: por uma antropologia da territorialidade. Brasília: Universidade de Brasília, 2002. (Série Antropologia, n. 322).

MARÉS, Carlos Frederico. A função social da terra. Porto Alegre: Sergio Antonio Fabris Editor, 2003.

MARTINS, José de Sousa. Fronteira: a degradação do outro nos confins do humano. 2. ed. São Paulo: Contexto, 2012.

MELATTI, Júlio Cezar. Índios do Brasil. São Paulo: Edusp, 2007.

NIMUENDAJÚ, Curt. The Serente. Los Angeles: Hodge Anniversary Publication Fund/Publications of the Frederick Web, 1942, v. 4.

OLIVEIRA, Ariovaldo Umbelino. A geografia agrária e as transformações territoriais recentes no campo brasileiro. In: CARLOS, Ana Fani Alessandri (Org.). Novos caminhos da geografia. 5. ed. 2. reimpressão. São Paulo: Contexto, 2010. (Caminhos da Geografia). 
O processo de conquista do território dos Akwẽ-Xerente no estado do Tocantins, pp. 61-85.

OLIVEIRA, João Pacheco de; FREIRE, Carlos Augusto da Rocha. A presença indígena na formação do Brasil. Brasília: Ministério da Educação, Secretaria de Educação Continuada, Alfabetização e Diversidade; LACED/Museu Nacional, 2006. (Série Vias dos Saberes, n. 2).

. Viagem da volta: etnicidade, política e reelaboração cultural no Nordeste indígena. 2. ed. Rio de Janeiro: Contra Capa Livraria/LACED, 2004.

OLIVEIRA-REIS, Francisco Carlos. Aspectos do Contato e Formas Socioculturais da Sociedade Akwẽ-Xerente (Jê). 2001. _f. Dissertação (Mestrado em Antropologia Social) - Universidade de Brasília. Instituto de Ciências Sociais, Departamento de Antropologia, Brasília, 2001.

PRADO JUNIOR, Caio. História Econômica do Brasil. 30. ed. São Paulo: Editora Brasiliense, 1984.

RAFFESTIN, Claude. Por uma geografia do poder. Trad. Rosemarie Zenith de Oliveira. São Paulo: Ática, 2011.

RIBEIRO, Darcy. Os índios e a civilização: a integração das populações indígenas no Brasil moderno. São Paulo: Companhia das Letras, 1996.

O povo brasileiro: a formação e o sentido do Brasil. São Paulo: Companhia das Letras, 2006. 